\title{
Synthesis and Characterization of some Transition metal complexes derived from Bidentate Schiff Base Ligand
}

\author{
Anita Sharma ${ }^{1}$ and Manish Shah ${ }^{2 *}$ \\ ${ }^{1}$ Department of Chemistry, Saurashtra University Rajkot, Gujarat, India \\ ${ }^{2}$ Department of Chemistry, Saurashtra University Rajkot, Gujarat, India
}

\begin{abstract}
A new Schiff base has been synthesized from 3-(3-nitrophenyl)-1-phenyl-1H-pyrazole-4carbaldehyde and O-amino phenol. Metal complexes of the Schiff base have been synthesized from acetate salt of $\mathrm{Cu}(\mathrm{II}), \mathrm{Co}(\mathrm{II})$ and $\mathrm{Ni}$ (II) metal in the alcoholic medium. The newly prepared Schiff base ligand and metal complexes have been characterized by various physicochemical techniques such as Elemental analysis, Magnetic moment, molar conductance method, UV/ Visible, IR, ${ }^{1} H N M R,{ }^{13} \mathrm{C} N M R$ spectral technique and thermo gravimetric studies. On the basis of elemental and spectral studies, six coordinated geometry was assigned to these complexes. In the presence of these results, it is suggested that this ligand act as a bidentate ligand. UV/Visible, IR and TGA studies confirmed the presence of the coordinated water molecules in the metal complexes.
\end{abstract}

Keywords: Schiff base, Metal complex, Spectral studies.

\section{Introduction}

Coordination chemistry is an important branch of inorganic chemistry since the appearance of water on earth aqua complex ion of metal must have existed [1]. Schiff bases have often been used as chelating ligands in coordination chemistry [2-3], they are more effective as a chelating agent when they bear supporting and stabilizing group like $-\mathrm{OH}$ close to $-\mathrm{HC}=\mathrm{N}$ - group. Bidentate group containing imine groups have also been used as the modulators of structure and electronic properties of transition metal centers. The ligand Schiff base finds its applications as the analytical reagent for determination of metals [4-5]. Transition metal complexes containing the Schiff base ligands have been interest for many years [6-8]. In this work, we report the results of our studies on the synthesis and spectral properties of Schiff base and its $\mathrm{Cu}$ (II), Ni (II) and Co (II) metal complexes.

\subsection{Material and method}

\section{Experimental}

All the chemicals used were of AR grade. Cobalt (II), Nickel (II) and Copper (II) used as acetate salts were of Merck. Pyrazole aldehyde was synthesized by very well-known Vilsmeier-Haack [9] reaction and purified by usual separation methods. Elemental analyses were carried out on EURO EA-3000 RS-232. IR spectra were recorded on 8400 FTIR Simadzu spectrometer. ${ }^{1}$ HNMR spectra of the ligand and complexes in DMSO- $\mathrm{d}_{6}$ were recorded on a Bruker Advance II 400 Spectrometer at room temperature using TMS as internal standard. UV-Visible spectra were recorded on Shimadzu Pharmaspec UV-1700 UV visible spectrometer. Mass spectra of ligands were recorded on GC-MS QP-2010 spectrometer. The ESI mass spectra of metal complexes were recorded on micromass Q-Tof Micro spectrometer. Thermal analyses have been carried out by using Schimadzu (TGA-50H) from room temperature to $1000^{\circ} \mathrm{C}$ under heating rate of $15^{\circ} \mathrm{C}$ $\min ^{-1}$.

\subsection{Preparation of Schiff base}

The Schiff base was prepared by condensation of 3-(3-nitrophenyl)-1-phenyl-1H-pyrazole-4carbaldehyde $(0.01 \mathrm{~mol})$ with $o$-amino phenol $(0.01 \mathrm{M})$ in ethanol $(30 \mathrm{ml})$, and the mixture was refluxed for 8 hrs. The progress of reaction was monitored by TLC (solvent system, benzene: acetone- 8:2). After completion of the reaction, the reaction mixture was poured over crushed ice. The separated solid product was filtered and washed with cold saturated sodium bisulphate solution and recrystallized with ethanol. 
<smiles>O=Cc1cn(-c2ccccc2)nc1-c1cccc([N+](=O)[O-])c1</smiles>

3-(3-nitrophenyl)-1-phenyl-1Hpyrazole-4-carbaldehyde<smiles>Nc1ccccc1O</smiles>

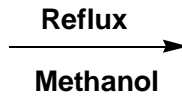<smiles>O=[N+]([O-])c1cccc(-c2nn(-c3ccccc3)cc2/C=N/c2ccccc2O)c1</smiles>

(E)-2-((3-(3-nitrophenyl)-1-phenyl-1 H-pyrazol-4yl)methyleneamino)phenol

Ligand

\section{Scheme-1}

\subsection{Synthesis of metal complexes}

A solution of the metal salt $(0.005 \mathrm{~mol})$ mixed drop wise with the solution of Schiff base $(0.01 \mathrm{~mol})$ in $20 \mathrm{ml}$ ethanol. The mixture was refluxed for 48 hours in $70-80^{\circ} \mathrm{C}$ on water bath. On cooling, colored solid product was collected by filtration and then washed several times with hot ethanol until the washing becomes colorless. The product was dried in air and stored in desiccators over anhydrous $\mathrm{CaCl}_{2}$ under vacuum. All the metal complexes were colored and stable in air and moisture.

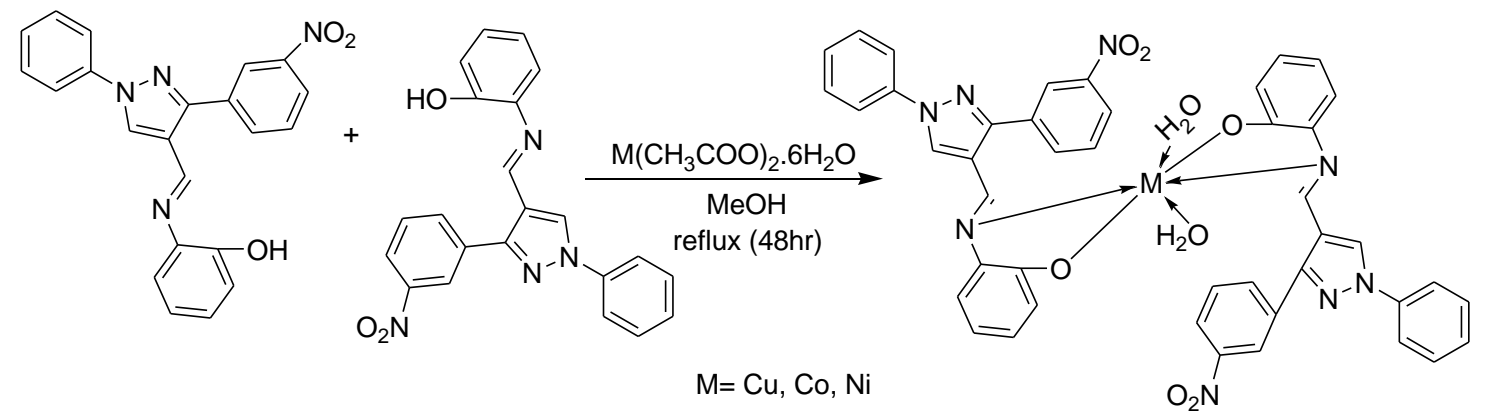

Scheme-2

III. Result and Discussion

The analytical and physical data of Schiff base ligand and its metal complexes are given in table-1. The data shows that the ligand L forms a 1:2 (M: L) complexes with $\mathrm{Cu}$ (II), Ni (II), Co (II), ions. The prepared complexes were found to have the general formulae $\left[\mathrm{M}(\mathrm{L})_{2} \cdot \mathrm{n} \cdot \mathrm{H}_{2} \mathrm{O}\right]$. Where $\mathrm{M}=\mathrm{Cu}$ (II), Ni (II), Co (II), $\mathrm{n}=2$ and $\mathrm{L}$ is Schiff base ligand. it coordinates as an anion by losing proton of the phenolic group. The charge on the complex was neutralized by the ligand L. Thus, the complexes were neutral in DMSO.

Table-1: Physical characteristics and analytical data of the complexes

\begin{tabular}{|c|c|c|c|c|c|}
\hline Compound & Formula & Colour & $\begin{array}{l}\text { M.P/D.P } \\
\left({ }^{\circ} \mathrm{C}\right)\end{array}$ & Yield (\%) & $\Lambda_{\mathrm{m}}\left(\Omega^{-1} \mathrm{~cm}^{2} \mathrm{~mol}\right.$ \\
\hline $\mathrm{L}$ & $\mathrm{C}_{22} \mathrm{H}_{16} \mathrm{~N}_{4} \mathrm{O}_{3}$ & Orange & 144 & $90 \%$ & - \\
\hline$\left[\mathrm{Cu}(\mathrm{L})_{2} \cdot 2 \mathrm{H}_{2} \mathrm{O}\right]$ & $\mathrm{C}_{44} \mathrm{H}_{34} \mathrm{CuN}_{8} \mathrm{O}_{8}$ & Dark brown & 344 & $72 \%$ & 3.42 \\
\hline$\left[\mathrm{Co}(\mathrm{L})_{2} .2 \mathrm{H}_{2} \mathrm{O}\right]$ & $\mathrm{C}_{44} \mathrm{H}_{34} \mathrm{CoN}_{8} \mathrm{O}_{8}$ & Green & 335 & $70 \%$ & 3.55 \\
\hline$\left[\mathrm{Ni}(\mathrm{L})_{2} .2 \mathrm{H}_{2} \mathrm{O}\right]$ & $\mathrm{C}_{44} \mathrm{H}_{34} \mathrm{NiN}_{8} \mathrm{O}_{8}$ & $\begin{array}{l}\text { Yellowish } \\
\text { brown }\end{array}$ & 346 & $68 \%$ & 4.29 \\
\hline
\end{tabular}

\subsection{Molar conductance}

Molar conductance of the complexes was measured in DMSO at a concentration of $0.001 \mathrm{M}$. The observed conductance values fall in the range of 1-20 Ohm- ${ }^{1} \mathrm{~cm}^{2}$ mol- ${ }^{1}$; indicate that the complexes were nonelectrolyte in nature. The $\mathrm{C}, \mathrm{H}$, and $\mathrm{N}$ analysis of Schiff base ligand and its metal complexes were found in good agreement with the expected values. 


\subsection{IR spectra and mode of bonding}

The IR spectral data of some important functional groups of the Schiff base ligand and its transition metal complexes presented in table-2. The IR spectrum of the Schiff base ligand showed strong absorption bands at $1656 \mathrm{~cm}^{-1}$ and $3417 \mathrm{~cm}^{-1}$, which attributed to the characteristic band of the azomethine $(-\mathrm{HC}=\mathrm{N}-)$ and phenolic (-OH) group respectively. These frequencies were shifted towards the lower wave number by 15-30 $\mathrm{cm}^{-1}$ in the spectra of metal complexes suggested the coordination of nitrogen of the azomethine group to the central metal atom in these complexes [10-11]. All the complexes exhibit a broad band in the region 3200-3453 $\mathrm{cm}^{-1}$ were assigned to the $v(-\mathrm{OH})$ of water, which indicate the presence of lattice or coordinated water molecule [12]. All the IR data suggested that the metal was bonded to the Schiff bases through the phenolic oxygen and the imino nitrogen [13]. The metal to nitrogen bond was detected at frequencies in the region $400-550 \mathrm{~cm}^{-1}$ from the IR data. This was confirmed by the presence of the new bands which may be assigned $v(\mathrm{M}-\mathrm{N}), v(\mathrm{M}-\mathrm{O})$. The IR spectra of $\mathrm{Cu}$ (II) metal complex presented in fig.1.

Table-2: Characteristic IR stretching bonds of Schiff base ligand and its metal complexes in $\mathrm{cm}^{-1}$

\begin{tabular}{|l|c|c|c|c|c|c|}
\hline Compound & $\mathbf{v}(\mathbf{H} 2 \mathrm{O})$ & $\mathbf{v}(\mathbf{C = N})$ & $\mathbf{v}(\mathbf{O H})$ & $\mathbf{v}(\mathrm{N}-\mathrm{N})$ & $\mathbf{v}(\mathbf{M}-\mathbf{N})$ & $\mathbf{v}(\mathbf{M}-\mathbf{O})$ \\
\hline $\mathrm{L}($ ligand $)$ & - & 1656 & 3417 & 1049 & - & - \\
\hline $\mathrm{Cu}(\mathrm{L})_{2} \cdot \mathrm{nH}_{2} \mathrm{O}$ & 3292 & 1593 & - & 1089 & 542 & 426 \\
\hline $\mathrm{Co}(\mathrm{L})_{2} \cdot \mathrm{nH}_{2} \mathrm{O}$ & 3371 & 1595 & - & 1070 & 491 & 424 \\
\hline $\mathrm{Ni}(\mathrm{L})_{2} \cdot \mathrm{nH}_{2} \mathrm{O}$ & 3321 & 1590 & - & 1066 & 530 & 420 \\
\hline
\end{tabular}

\section{$3.3{ }^{1} \mathrm{H}$ NMR spectra}

The ${ }^{1} \mathrm{H}$ NMR spectrum of the Schiff base ligand was recorded in DMSO- $\mathrm{d}^{6}$. In the ${ }^{1} \mathrm{HNMR}$ spectra of Schiff base ligand, a peak appeared at $9.27 \mathrm{ppm}$ was assigned to the proton of phenolic group and a singlet peak appeared at $8.75 \mathrm{ppm}$ was assigned to protons of azomethine group.

\section{$3.4{ }^{13}$ CNMR spectra}

The ${ }^{13} \mathrm{C}$ NMR spectrum of the Schiff base ligand was recorded in DMSO-d $\mathrm{d}^{6}$. In the ${ }^{13} \mathrm{C}-\mathrm{NMR}$ spectra of the metal complexes, the signal appeared at 198ppm was assigned to azomethine carbon atoms $(\mathrm{C}=\mathrm{N})$. A signal at $158 \delta$ was assigned for phenolic carbon. Phenyl rings of ligand showed following signals 114.34; $115.25,115.52$, 118.27, $118.55,119.02,119.40,119.95,121.84,122.80,126.75,126.97,129.25,129.72$, $129.99,137.50,139.08,150.74,151.15,152.76 \delta \mathrm{ppm}$.

\subsection{Mass spectra of the compounds}

The mass spectral data of Schiff base ligand and its metal chelates are given in table-3. Mass spectra of the ligand and its metal complexes showed molecular ion peaks, which were in good agreement with the expected values. The mass spectrum of ligand $\mathrm{L}$ gives a peak at $384 \mathrm{~m} / \mathrm{z}$, which was assigned for [HL] peak. Copper and cobalt complexes give a molecular ion peak at 866 and $864 \mathrm{~m} / \mathrm{z}$ respectively, which assigned as [M] and $[\mathrm{M}+3]$ peak. The mass spectrum of Ni (II) complex showed a peak at $866 \mathrm{~m} / \mathrm{Z}$ which was assigned for $[\mathrm{M}+5]$ peak.

Table-3: Mass spectral data of Schiff base ligand and its metal complexes

\begin{tabular}{|c|c|c|c|c|}
\hline S.No. & Compound & Cal. Mass & Obtained mass & Peak assigned \\
\hline $\mathbf{1}$ & $\mathrm{C}_{22} \mathrm{H}_{16} \mathrm{~N}_{4} \mathrm{O}_{3}$ & 384 & 384 & {$[\mathrm{M}]$} \\
\hline $\mathbf{2}$ & $\mathrm{C}_{44} \mathrm{H}_{34} \mathrm{CuN}_{8} \mathrm{O}_{8}$ & 866.34 & 866.34 & {$[\mathrm{M}]$} \\
\hline $\mathbf{3}$ & $\mathrm{C}_{44} \mathrm{H}_{34} \mathrm{CoN}_{8} \mathrm{O}_{8}$ & 861.72 & 864 & {$[\mathrm{M}+3]$} \\
\hline $\mathbf{4}$ & $\mathrm{C}_{44} \mathrm{H}_{34} \mathrm{NiN}_{8} \mathrm{O}_{8}$ & 860 & 865 & {$[\mathrm{M}+5]$} \\
\hline
\end{tabular}

\subsection{Magnetic moment and electronic absorption spectra}

The electronic absorption spectral data and magnetic moment values of Schiff base ligand and its transition metal complexes are given in table-4. The electronic spectrum of Schiff base ligand exhibit strong absorption bands at $282 \mathrm{~nm}$ and $294 \mathrm{~nm}$, which were attributed to $\pi-\pi^{*}$ and $\mathrm{n}-\pi^{*}$ transitions respectively [14]. The observed magnetic momentum value of $\mathrm{Cu}$ (II) complex was $1.75 \mathrm{BM}$, falls within the range observed for distorted octahedral geometry [15]. UV/Visible spectra of $\mathrm{Cu}$ (II) complex presented in fig.2. The magnetic moment value of $\mathrm{Ni}$ (II) complex was found to be $3.23 \mathrm{BM}$, falls within the range of 2.8-3.5 BM for metal complexes, suggesting octahedral geometry [16]. The magnetic moment of Co (II) complex has been found to be 4.94 B.M, and it lies within the range expected for octahedral geometry [17]. 
Table-4: Electronic absorption spectral data and magnetic moment values of Schiff base ligand and its transition metal chelates

\begin{tabular}{|c|c|c|c|c|}
\hline Compound & $\begin{array}{c}\text { Absorption in } \\
\text { nm }\end{array}$ & Transitions & $\begin{array}{c}\text { Mag. Moment } \\
\text { (B.M.) }\end{array}$ & Geometry \\
\hline $\mathrm{C}_{22} \mathrm{H}_{16} \mathrm{~N}_{4} \mathrm{O}_{3}$ & $282,294$. & $\pi-\pi^{*}, \mathrm{n}-\pi^{*}$ & - & \\
\hline $\mathrm{C}_{44} \mathrm{H}_{34} \mathrm{CuN}_{8} \mathrm{O}_{8}$ & 740 & ${ }^{2} \mathrm{E}_{\mathrm{g}} \rightarrow{ }^{2} \mathrm{~T}_{2 \mathrm{~g}}$ & 1.75 & Octahedral \\
\hline & 431 & ${ }^{4} \mathrm{~T}_{1 \mathrm{~g}}(\mathrm{~F}) \rightarrow{ }^{4} \mathrm{~T}_{2 \mathrm{~g}}(\mathrm{~F})$ & 4.59 & Octahedral \\
$\mathrm{C}_{44} \mathrm{H}_{34} \mathrm{CoN}_{8} \mathrm{O}_{8}$ & 439 & ${ }^{4} \mathrm{~T}_{1 \mathrm{~g}}(\mathrm{~F}) \rightarrow{ }^{4} \mathrm{~A}_{2 \mathrm{~g}}(\mathrm{~F})$ & & \\
& 727 & ${ }^{4} \mathrm{~T}_{1 \mathrm{~g}}(\mathrm{~F}) \rightarrow{ }^{4} \mathrm{~T}_{1 \mathrm{~g}}(\mathrm{P})$ & & Octahedral \\
\hline & 415 & ${ }^{3} \mathrm{~A}_{2 \mathrm{~g}}(\mathrm{~F}) \rightarrow{ }^{3} \mathrm{~T}_{2 \mathrm{~g}}(\mathrm{~F})$ & 3.32 & \\
$\mathrm{C}_{44} \mathrm{H}_{34} \mathrm{NiN}_{8} \mathrm{O}_{8}$ & 433 & ${ }^{3} \mathrm{~A}_{2 \mathrm{~g}}(\mathrm{~F}) \rightarrow{ }^{3} \mathrm{~T}_{1 \mathrm{~g}}(\mathrm{~F})$ & & \\
& 765 & ${ }^{3} \mathrm{~A}_{2 \mathrm{~g}}(\mathrm{~F}) \rightarrow{ }^{3} \mathrm{~T}_{1 \mathrm{~g}}(\mathrm{P})$ & & \\
\hline
\end{tabular}

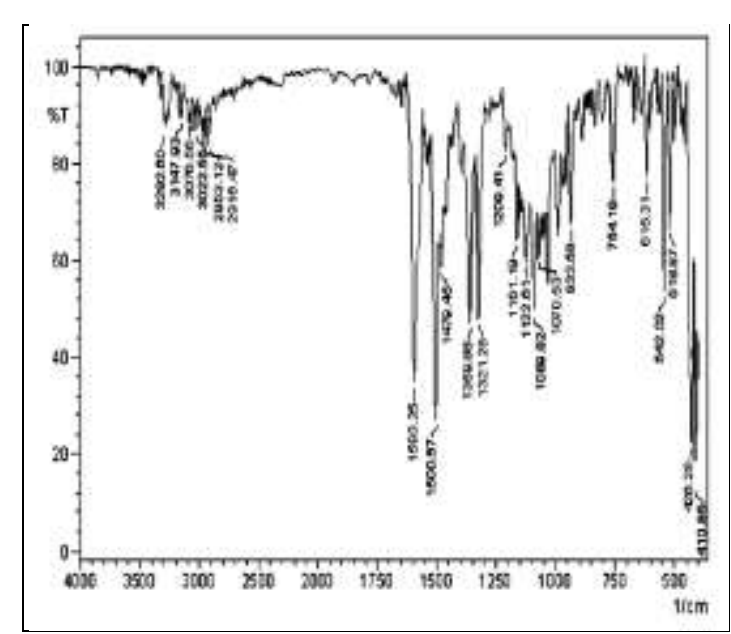

Fig-1:-IR spectra of Cu (II) Complex

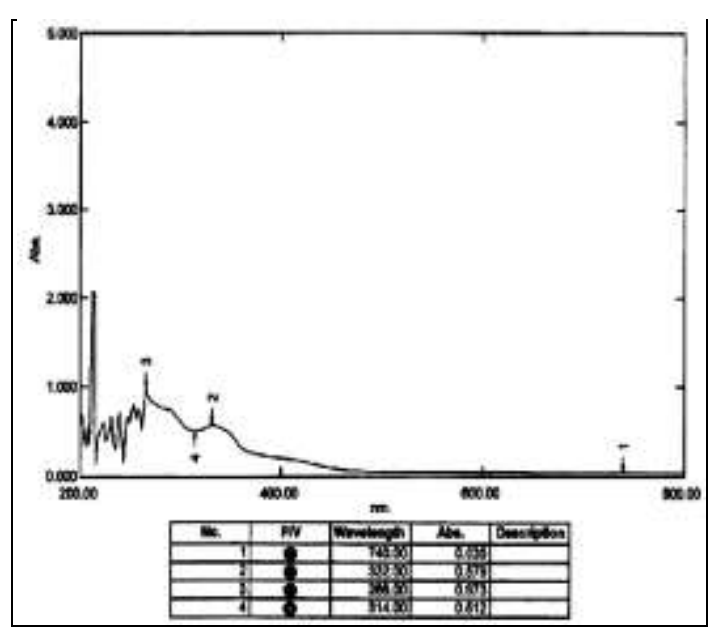

Fig-2:-UV/Visible spectra of $\mathrm{Cu}$ (II) Complex

\subsection{Thermal analysis}

Thermal stability of complexes was studied in the range of $50-1000^{\circ} \mathrm{C}$ by controlling heating rates $15^{\circ} \mathrm{C} /$ minute. The TG curve for $\mathrm{Cu}$ complex showed weight loss initially at $90^{\circ} \mathrm{C}(4.0 \%)$ which indicate the presence of lattice water molecules in complex. Weight loss at $257.1^{0} \mathrm{C}(7.5 \%)$ indicate the coordinated water molecule in the metal complexes. The percentage wt. loss indicates 1.5 molecule of water. The complex then after starts decomposing above $257^{\circ} \mathrm{C}$, and it completely decomposed at $550^{\circ} \mathrm{C}$, which correspond to $85 \%$ weight loss. Above $550^{\circ} \mathrm{C}$ complex gets converted into $\mathrm{CuO} / \mathrm{Cu}$ metal residue. Thermo gravimetric study of $\mathrm{Co}$ (II) complex showed three steps thermogram curve. Weight loss up to $236^{\circ} \mathrm{C}(7.6 \%)$ indicates the presence of lattice and coordinates water molecules. Above $236^{\circ} \mathrm{C}$, the loss was continuous in two steps and at $6500^{\circ} \mathrm{C}$ ligand was completely decomposed $(87 \%)$. Above $650^{\circ} \mathrm{Ccomplex}$ converted into $\mathrm{CoO} / \mathrm{Co}$ metal residue. Thermo gram curve of $\mathrm{Ni}$ (II) complex also showed three steps decomposition pattern. Weight changes up to $297^{\circ} \mathrm{C}$ indicate the loss of two lattice and two coordinated water molecules. The loss of mass at this stage is $8.4 \%$, which was very well agreement with calculated value [8.45\%]. Above $297^{\circ} \mathrm{C}$, the loss is continuous in two stages and at $778^{\circ} \mathrm{C}$, the complex gets converted into $\mathrm{NiO} / \mathrm{Ni}$ metal residue. The thermo gravimetric analysis (TGA) provides authentic information regarding the presence of water molecules in the coordination sphere of all complexes [18]. The TGA curves of all metal complexes are presented in Fig-3, 4 and 5. 


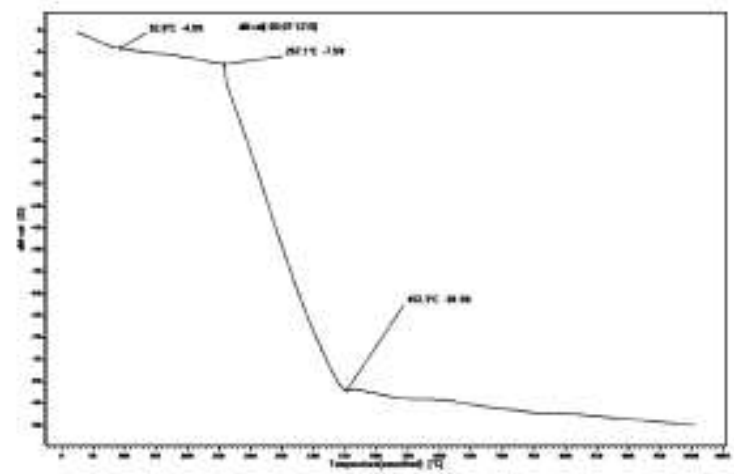

Fig-3:-TGA curve of $\mathrm{Cu}$ (II) metal complex

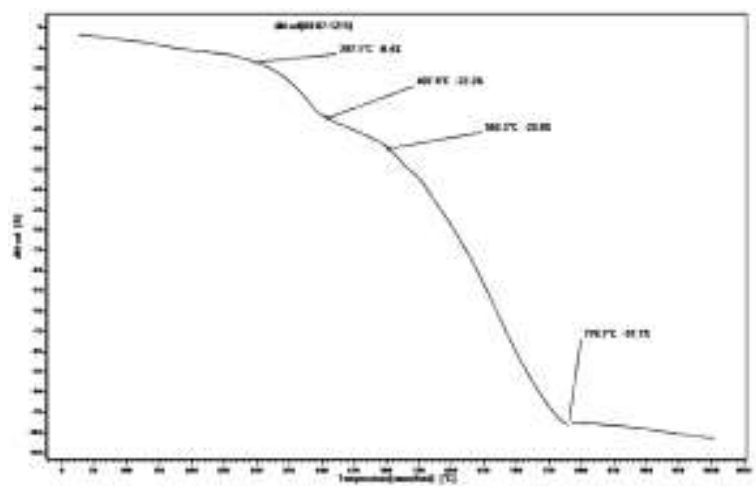

Fig-4:-TGA curve of Co (II) metal complex

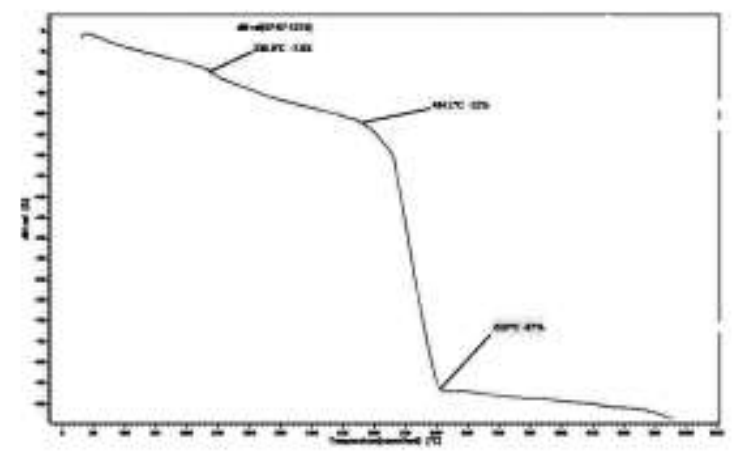

Fig-5:- TGA Curve of Ni (II) metal complexe

\section{Conclusion}

2-(3-(3-nitrophenyl)-1-phenyl-1H-pyrazole-4-yl) methylene amino) phenol and its transition metal complexes have been synthesized in 2:1 molar ratio of ligand to metal ion. They have been characterized by the analytical, spectral, thermal and magnetic studies. The results of these investigations support the suggested structure of the metal complexes. Molar conductance values, analytical data suggests that the complexes are neutral in DMSO [19]. The UV/Visible spectrum and value of magnetic susceptibility suggest the octahedral geometry of complexes. Thermal analysis of metal complexes indicates the presence of coordinated water molecules in the complexes. TGA supported the octahedral environment around the metal ion. Complete analysis suggests a plausible octahedral structure of metal complex.

\section{Acknowledgement}

Authors are thankful to Head, Dept.of Chemistry Saurashtra University for providing necessary facilities, UGC New Delhi for the award of meritorious fellowship and SAIF Chandigarh, for ESI mass, ${ }^{1} \mathrm{HNMR}$ and ${ }^{13} \mathrm{CNMR}$ analysis.

\section{References}

[1] G. Wilkinsons. R.D. Willard and J.A. McGleverty "Comprehensive coordination chemistry, the synthesis reaction properties and applications of coordination chemistry, (Pergamon Press, Vol. 6,1987).

[2] Y. Y. Shibuya, K. Nabari, M. Kondo, S. Yasue, K. Maeda, F. Uchida, H. Kawaguchi. Chem. Lett., 37, 2008, 78

[3] A. Roth, J. Becher, C. Herrmann, H. Gorls, G. Vaughan, M. Reiher, D. Klemm, W. Plass. Inorg. Chem., 45, 2006, 10066.

[4] A. Praveen kumar, P. R. reddy and V.K. Reddy, J. Korean. Chem. Soc., 51, 2007, 331.

[5] R.B. Singh and H.Ishii, Critical review in analytical chem., 22, 1991, 381.

[6] S.Chang, L.Jones, C.M.Wang, L.M Henling and R. H.Gruubees Organomatallics., 17, 1998, 3460.

[7] K.K. Chturvedi, J . Inorg. Nucl. Chem., 39, 1977,901.

[8] R.D. Archer and B. Wang, Inorg. Chem., 29, 1990, 39.

[9] Ambika Shrivastava \& R.M. Singh, Indian journal of Chemistry, vol.44B, 2005

[10] G.G. Mohamed and Z.H. Abd El-Wahab, J. Thermal Ana. And Colorimetry, 73(1), 2003, 347-380.

[11] A. I. Magdy and K.M. El-Mahdy, Phosphorous, Sulfur, and Silicon, 184, 2009, 2945.

[12] G.Xue, Z.Juenfong, G.Shin, Y. Wu, B.Shuen, J. Chem. Soc Perkin Trans. II , 1989, 33.

[13] Wang G. Chang, J.C. Synth, Re. act. Inorg. Met-Org. Chem, 24, 1091. (1994).

[14] E. Conpolat and M. Kaya, J. Coord. Chem., 57(14), 2004, 1217-1223.

[15] D. Koushik, R.Jagnyeswar, M.Mario, W.Xin-Yi, G.Song, B.Pradyot, Journal of Inorganic Biochemistry, 101(1), 2007, 95-103.

[16] ABP Lever, J. Chem. Edu., 45(11), 1968 711-712.

[17] B N Figgis, An introduction to ligand fields (New Delhi, Wiley Eastern, 1976).

[18] M.S Masoud, S.A Abou EI-Enein, H.M.Kamel, India J.Chem.41 A, 2002297.

[19] W.J.Geary, Coord.Chem.Rev. 7, 1971, 81-122. 